\title{
Mixed cryoglobulinemia-associated Sjögren's syndrome leading to spontaneous rupture of the kidney: a case report
}

This article was published in the following Dove Press journal:

International Medical Case Reports Journal

23 March 2016

Number of times this article has been viewed

\author{
Intissar Haddiya' \\ Hakim Hamzaoui' \\ Zitouna Alhamany ${ }^{2}$ \\ Fatime-zohra Berkchi' \\ Hakima Rhou' \\ Loubna Benamar' \\ Naima Ouzeddoun' \\ Rabea Bayahia' \\ 'Department of Nephrology- \\ Dialysis-Renal Transplantation, Ibn \\ Sina University Hospital, Rabat, \\ Morocco; ${ }^{2}$ Department of Pathology, \\ Rabat Children's Hospital, Ibn Sina \\ University Hospital, Rabat, Morocco
}

Background: Spontaneous rupture of the kidney is uncommon and is mainly caused by renal tumors. Only a few cases are caused by vasculitis. We report here the first case of spontaneous rupture of kidney resulting from mixed cryoglobulinemia.

Case presentation: A 44-year-old man presented with sudden onset of fever, acute pulmonary edema, left flank abdominal pain unassociated with trauma, and rapidly progressive renal failure requiring dialysis. Computed tomography of the abdomen revealed a large perirenal hematoma of the left kidney. During conservative surgery, the patient underwent renal biopsy that showed renal vasculitis and membranoproliferative glomerulonephritis with intracapillary microthrombi. Tests were positive for mixed cryoglobulinemia caused by Sjögren's syndrome. The patient was better after immunosuppressive therapy, with the disappearance of clinical symptoms and the recovery of baseline renal function.

Conclusion: We report on this case and discuss a possible link between spontaneous rupture of kidney and mixed cryoglobulinemia-associated Sjögren's syndrome.

Keywords: mixed cryoglobulinemia, Sjögren's syndrome, spontaneous rupture of kidney, renal hematoma, Wünderlich syndrome

\section{Introduction}

Spontaneous rupture of kidney (SRK) is uncommon. In most cases, it was a complication of benign or malignant kidney tumors. Only a few cases are a result of systemic vasculitis, particularly polyarteritis nodosa (PAN), microscopic polyangiitis, and in sporadic reports, Wegener's granulomatosis. To our knowledge, SRK has never been associated with mixed cryoglobulinemia.

\section{Case presentation}

A 44-year-old white man was admitted to our hospital because of acute pulmonary edema. His past medical history was significant for chronic tobacco use and recurrent episodes of arthralgias over the course of 2 years, which were treated symptomatically by the patient by self-medication with analgesics, without any specific medical management.

The patient had been well until 2 months earlier, when he began to have worsening of his physical state, anorexia, weakness, weight loss, and diffuse myalgias. Three days before admission, he complained of acute left flank pain unassociated with trauma. It was sudden in onset, intense, and associated with nausea. In addition, the patient reported a significant decrease of urine volume $(<0.5 \mathrm{~L}$ urine in 24 hours $)$ and dyspnea. Physical examination showed high blood pressure $(170 / 100 \mathrm{mmHg})$, his temperature
Correspondence: Intissar Haddiya Département of Nephrology, Ibn Sina University Hopital, Rue Famfda Cherkaoui Rabat-Instituts, BP 6527, Rabat, Morocco

Tel +2 I2 665883643

Email intissarhaddiya@hotmail.com
International Medical Case Reports Journal 20|6:9 77-8I

(c) (1) (\$) 2016 Haddiya et al. This work is published by Dove Medical Press Limited, and licensed under Creative Commons Attribution - Non Commercial (unported, v3.0) (c) permission from Dove Medical Press Limited, provided the work is properly attributed. Permisisions beyond the scope of the License are administered by Dove Medical Press Limited. Information on how to request permission may be found at: http://www.dovepress.com/permissions.php
Dovepress

http://dx.doi.org/10.2147/IMCRI.\$64262 
was $38.7^{\circ} \mathrm{C}$, and his respiratory rate was 34 breaths per minute. His weight was $71 \mathrm{~kg}$ (he weighed $81 \mathrm{~kg} 2$ months earlier). Chest auscultation revealed bilateral rales. Cardiac examination findings were unremarkable. The abdomen was tender, mainly over the left upper quadrant, and had no palpable hepatosplenomegaly. He had 1+ lower-extremity edema. Exam of the lower limb found petechial purpura on his left leg, with livedo reticularis. Otherwise, the examination was normal.

Laboratory findings revealed a rapidly progressive renal failure with a serum creatinine level of $1.71 \mathrm{mg} / \mathrm{dL}$ (normal value, $0.6-1.2 \mathrm{mg} / \mathrm{dL}$ ), which increased to $4.02 \mathrm{mg} / \mathrm{dL}$ over the next 2 days; a blood urea nitrogen level of $57 \mathrm{mg} / \mathrm{dL}$ (normal value, 7-20 mg/dL), which also increased to $123 \mathrm{mg} / \mathrm{dL}$; a hypervolemic hyponatremia of $124 \mathrm{mEq} / \mathrm{L}$ (normal value, 135-145 mEq/L); and normal serum electrolytes otherwise. Twenty-four hour urinary protein levels were $0.6 \mathrm{~g} / 24$ hours (normal value, $<0.03 \mathrm{~g} / 24$ hours), and urinary sediment was positive for microscopic hematuria. Hemoglobin was $9.7 \mathrm{~g} / \mathrm{dL}$ (normal value, 13-16 g/dL), white blood cell count was $18,300 / \mathrm{mm}^{3}$ (normal value, $4,000-1,000 / \mathrm{mm}^{3}$ ), and platelets were $626,000 / \mathrm{mm}^{3}$ (normal value, $150,000-300,000 / \mathrm{mm}^{3}$ ). Erythrocyte sedimentation rate was $80 \mathrm{~mm} /$ hour (normal value, $<15 \mathrm{~mm} /$ hour), with a C-reactive protein level of $11.3 \mathrm{mg} / \mathrm{L}$ (normal value, 6-12 mg/L). Aminotransferase and creatinine kinase levels were normal. Lactate dehydrogenase levels were elevated (1,243 U/L; normal value, <250 U/L). CH50 was not checked, but complement component $\mathrm{C} 3$ was normal, at $80 \mathrm{mg} / \mathrm{dL}$ (normal, $80-170 \mathrm{mg} / \mathrm{dL}$ ), and C4 was strongly reduced, at $6 \mathrm{mg} / \mathrm{dL}$ (normal, 16-40 mg/dL). Rheumatoid factor and antinuclear antibodies were present. There was no monoclonal paraprotein detected both on serum and urine protein immuno-electrophoresis. In addition, five blood samples for cultures (both aerobic and anaerobic) were sent to the laboratory in view of the patient's fever, leukocytosis, and high erythrocyte sedimentation rate, all of which were negative.

Chest radiography showed cardiomegaly with bilateral pulmonary infiltrates, suggesting acute pulmonary edema. Renal ultrasound showed normal-sized kidneys without evidence of hydronephrosis, but it allowed us to identify a subcapsular renal hematoma that measured $63 \times 52 \mathrm{~mm}$ in the upper pole of the left kidney, which was confirmed by abdominal computed tomography (CT) scan (Figure 1A). Multislice computed angiotomography scanning identified the hematoma and ruled out microaneurysms of the main renal arteries, other vascular abnormalities, and renal tumors (Figure 1B). Hemodialysis therapy was started because of oliguria, continuous decrease of renal function, and persisting pulmonary edema despite high doses of furosemide $(500 \mathrm{mg} /$ day), and then the patient was operated on with conservative surgery for renal hematoma. A drain was placed and then withdrawn after 3 days.

Renal biopsy was performed, during surgery, the third day after admission and was submitted for light microscopic and immunofluorescence examination (Figure 2). The specimen consisted of renal medulla and cortex with 14 glomeruli. One glomerulus was globally sclerosed. Some glomeruli were ischemic. The preserved glomeruli were enlarged and showed diffuse mesangial expansion. There was significant hypercellularity of glomeruli with numerous infiltrating neutrophils, minimal endocapillary proliferation, and one cellular crescent. There were thickening and reduplication of the glomerular basal membrane, suggesting membranoproliferative glomerulonephritis. In two glomeruli, we noted intracapillary amorphous deposits compatible with microthrombi. Small vessels showed extensive necrotizing angiitis. Some vessels had also leukocytoclastic angiitis.
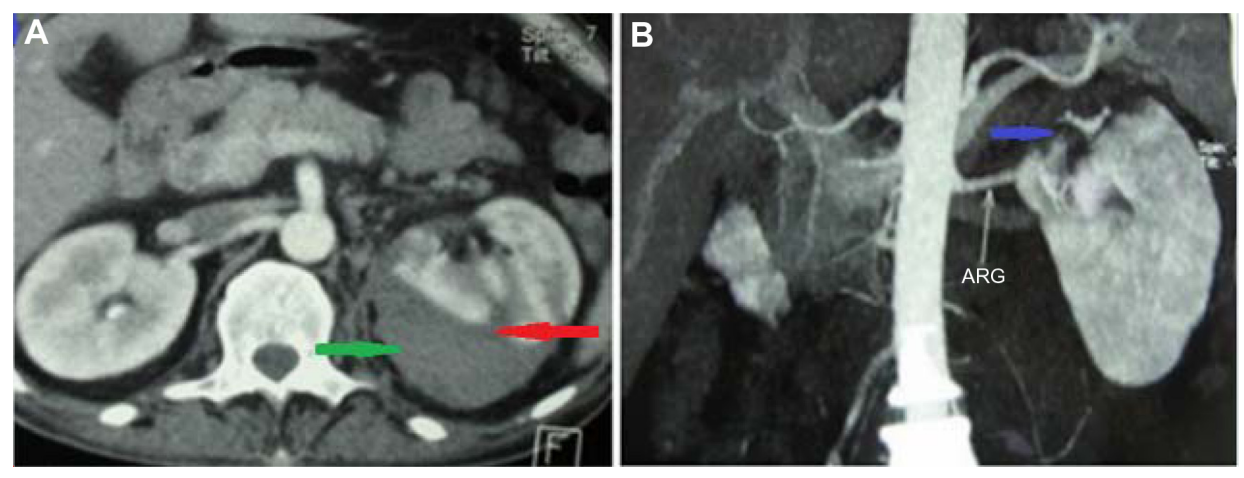

Figure I Renal computed tomography.

Notes: (A) Enhanced abdominal computed tomography scan shows rupture of the left kidney with perirenal hematoma (green arrow). The point of rupture is clearly seen (red arrow). (B) Sagittal reconstruction of the computed angiotomography scan showing normal left renal artery with avascular upper pole of left kidney corresponding to the area of rupture (blue arrow). 


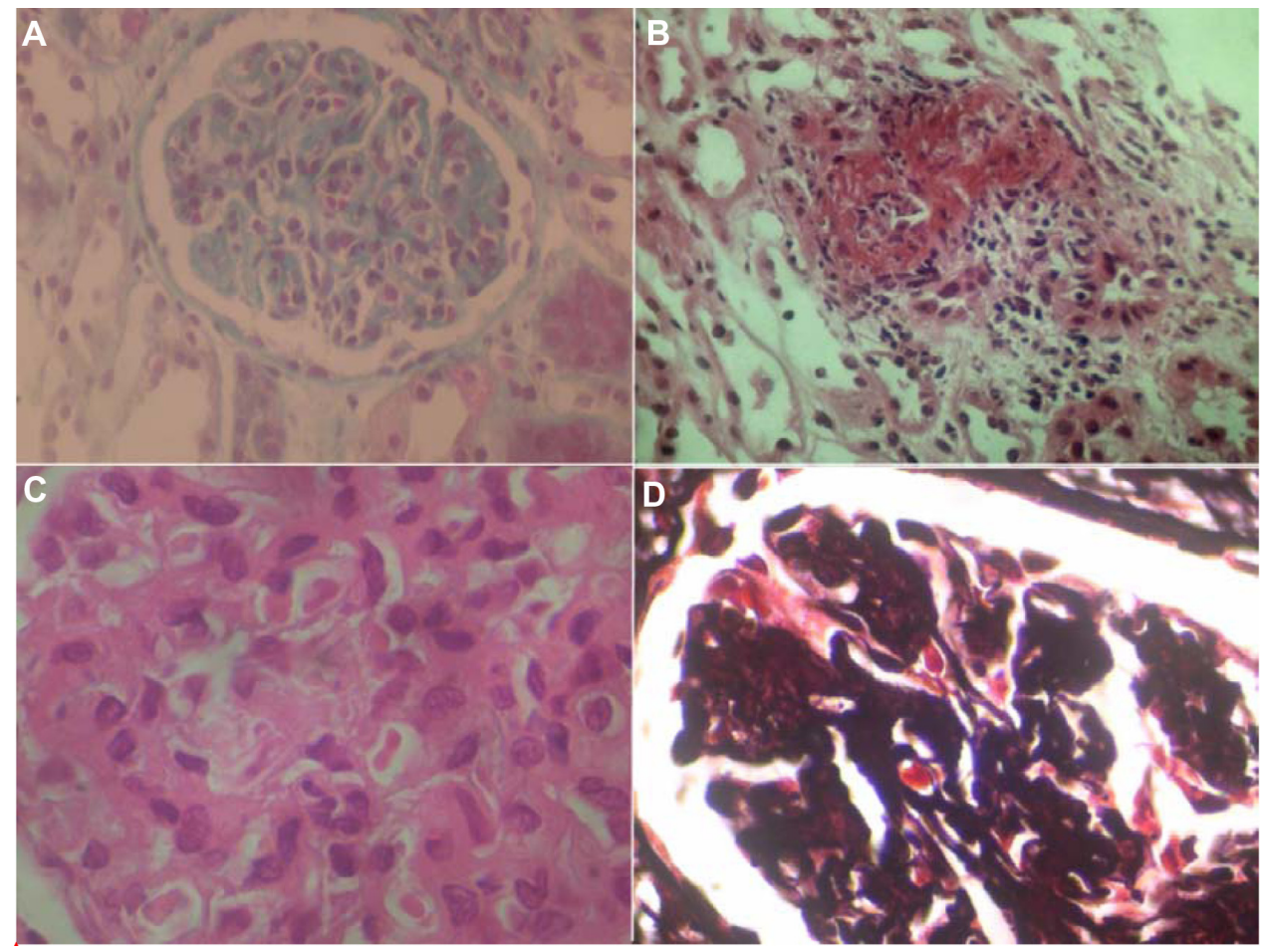

Figure 2 Renal biopsy specimen.

Notes: (A, B and D) Membrano proliferative glomerulonephritis with intracapillary microthrombi. (A) Trichrome stain; original magnification, $\times 400$. (B) Eosin and hematoxylin stain; original magnification, $\times 400$. (D) Jones silver methenamine stain; original magnification, $\times 600$. (C) Extensive necrotizing arteritis affecting an interlobular artery. Eosin and hematoxylin stain, magnification $\times 400$.

There was considerable tubular necrosis and interstitial edema with minimal leukocyte infiltrates. Unfortunately, the immunofluorescence sample did not contain glomeruli.

The patient underwent an extensive workup to determine the cause of his renal vasculitis. The laboratory tests were sent immediately after we received the kidney biopsy results, 72 hours after the biopsy had been performed. Serological studies for antineutrophil cytoplasmic antibodies, antiglomerular basement membrane antibodies, antidouble-stranded DNA antibodies, and anti-Smith antibodies were negative, excluding respectively pauci-immune vasculitis, Goodpasture's syndrome, and lupus vasculitis. There was neither apparent sepsis nor visceral abscess on computed tomography scan. Transthoracic echocardiography showed no vegetations, thus excluding infectious endocarditis. Skin-biopsy specimen of a purpuric lesion showed leukocytoclastic vasculitis without immunoglobulin A deposition, and therefore did not support the diagnosis of Henoch-Schönlein purpura. Tests for cryoglobulinemia were positive, including the presence of cryocrit (12\%) with type II mixed cryoglobulin (immunoglobulin G/immunoglobulin M kappa). We made additional investigations to determine the cause of mixed cryoglobulinemia, and assessment for hepatitis $\mathrm{C}$ virus (HCV) RNA and hepatitis B virus DNA by polymerase chain reaction was negative. Tests for Sjögren's syndrome were positive with the presence of anti-Ro (SS-A), anti-La (SS-B), lymphocytic infiltrate in minor salivary gland biopsy (grade 3 according to Chisholm and Mason grading system), and positive Schirmer's test. Screening for lymphoma remained negative despite initial elevated lactate dehydrogenase levels. There were neither peripheric or visceral adenopathies nor lymphomatic infiltration on osteomedullary biopsy. All these data confirmed that the patient had SRK caused by type II mixed cryoglobulinemiaassociated Sjögren's syndrome.

The patient received 3 days of pulses of methylprednisolone ( $1 \mathrm{~g} /$ day $)$, followed by oral prednisone $(1 \mathrm{mg} / \mathrm{kg} /$ day $)$ with a decreasing regimen and 6 monthly pulses of intravenous cyclophosphamide $(1 \mathrm{~g})$ as induction of remission. The patient remained febrile during hospitalization, with temperatures ranging between $38.5^{\circ} \mathrm{C}$ and $38.8^{\circ} \mathrm{C}$, until he received the third pulse of methyl prednisolone, which was administered 12 days after admission. Azathioprine (100 mg/ day) was started as maintenance treatment. The patient had spectacular improvement of his physical state. Arthralgias and the other symptoms disappeared, proteinuria fell to only trace amounts, and renal function returned to its baseline value $(0.9 \mathrm{mg} / \mathrm{dL})$ over the next 2 weeks, and $\mathrm{C} 4$ levels 
were again normal. Resorption of the renal hematoma was complete over the next 5 weeks. Cryoglobulins remained undetectable. Renal function and lactate dehydrogenase were still normal. Ethical approval was not needed in the present case report, because it didn't include research or experiments. There was no risk of causing harm or violating the patient's right, since it was presented in a way that respected the patient's privacy and confidentiality. The patient gave oral consent when informed that the data will be published.

\section{Discussion}

SRK, or Wünderlich syndrome, is a rare entity. It was first reported by Bonet in 1700 and later described in more detail by Wünderlich in $1856 .{ }^{1,2}$ To date, more than 200 cases have been reported in world literature. To the best of our knowledge, no similar case was described previously.

Several causes may lead to SRK. Tumors, particularly renal cell carcinoma and angiomyolipoma, are the most common cause of SRK, occurring in 57\%-73\% of cases. ${ }^{3,4}$ Vascular disease was reported in a meta-analysis of spontaneous renal hemorrhage as the next most common offender, with PAN occurring most frequently. ${ }^{5}$ Other vasculitis was also reported to be associated with SRK, especially microscopic polyangiitis and Wegener's granulomatosis. ${ }^{6-8}$ Our patient had SRK, probably as a result of vasculitis; however, he had neither PAN nor pauci-immune vasculitis. Microaneurysms and renal vessel thrombosis were not noted in computed angiotomography scan. Furthermore, the patient had also neither renal tumor, both in radiologic and histologic findings, nor renal infection. On the basis of clinical context and laboratory findings, we suggest that SRK was a result of cryoglobulinemic vasculitis associated with Sjögren's syndrome.

Mixed cryoglobulinemia is strongly associated with $\mathrm{HCV}$. Prevalence of HCV infection in patients with mixed cryoglobulinemia ranges from $30 \%$ to $96 \% .{ }^{9,10}$ The etiologies of negative-HCV mixed cryoglobulinemia are "essential" mixed cryoglobulinemia (27\%); lymphoproliferative disorders, especially B-non-Hodgkin's lymphoma and myeloma (26\%); autoimmune diseases, particularly Sjögren's disease and lupus (34\%); and infectious disease (13\%), including hepatitis B virus and HIV. ${ }^{11}$ In the study of Trejo et al, ${ }^{12}$ of 443 patients with cryoglobulinemia, 10\% had Sjögren's syndrome. Inversely, in large series of patients with Sjögren's syndrome, mixed cryoglobulinemia, especially type II, was present in $20 \%$ of cases and was characterized by a low CH50, cutaneous vasculitis, and poor prognosis resulting from more severe internal organ involvement and frequent evolution to malignant lymphomas. ${ }^{13-15}$
Vasculitis in Sjögren's syndrome can occur either as a cutaneous localized form (leukocytoclastic vasculitis) or as systemic necrotizing vasculitis involving small-sized and medium-sized arteries of various organs related to the presence of cryoglobulinemia. ${ }^{16}$ It is well known that in Sjögren's syndrome type B, there is aneurysmal dilatation of arteries. However, spontaneous rupture was rarely described. To the best of our knowledge, there are only three reports: Achkar et al described first a ruptured aneurysm of the inferior pancreaticoduodenal artery in the setting of rheumatoid vasculitis-associated Sjögren's syndrome, ${ }^{17}$ Curi et al reported a contained rupture of the visceral aorta in a patient with Sjögren's syndrome associated with osteoarthritis, ${ }^{18}$ and Klingler et al reported a rupture of a spinal artery aneurysm attributable to exacerbated Sjögren syndrome-associated cryoglobulinemic vasculitis. ${ }^{19}$ In contrast, it is also known that cryoglobulinemic vasculitis may induce injuries in the vascular wall. Herold et al described cryoglobulinemic vasculitis associated with aortic aneurysms in pediatric cases of Kawasaki disease, ${ }^{20}$ and Au et al reported structural aortic abnormalities in four patients with negative-HCV cryoglobulinemia, including multiple dissections, aneurysms, and congenital aortic arch abnormalities. ${ }^{21}$ Therefore, we presume that an exacerbation of the Sjögren's syndromeinduced cryoglobulinemic vasculitis with necrotizing arteritis and fibrinoid necrosis of the vessel's media led to weakening of the arterial wall, formation of kidney aneurysm, and spontaneous rupture. This mechanism may also explain the occurence of microaneurysms and SRK in PAN and in rare cases of microscopic polyangiitis and Wegener's granulomatosis. ${ }^{22-26}$

\section{Acknowledgments}

We gratefully acknowledge radiologist Dr Taoussi for abdominal computed angiotomography iconography. Written informed consent was obtained from the patient for this case to be published.

\section{Author contributions}

All authors made substantial contributions to conception and design, acquisition of data, or analysis and interpretation of data; took part in either drafting the article or revising it critically for important intellectual content; gave final approval of the version to be published; and agree to be accountable for all aspects of the work in ensuring that questions related to the accuracy or integrity of any part of the work are appropriately investigated and resolved. 


\section{Disclosure}

The authors report no conflicts of interest in this work.

\section{References}

1. Polkey HJ, Vynalek WJ. Spontaneous nontraumatic perirenal and renal hematomas. Arch Surg. 1933;26(2):196-204.

2. Wünderlich CRA. Handbuch der Pathologie und Therapie. 2nd ed. Stuttgart: Ebner and Seubert; 1856.

3. McDougal WS, Kursh ED, Persky L. Spontaneous rupture of the kidney with perirenal hematoma. $J$ Urol. 1975;114(2):181-184.

4. Morgentaler A, Belville JS, Tumeh SS, Richie JP, Loughlin KR. Rational approach to evaluation and management of spontaneous perirenal hemorrhage. Surg Gynecol Obstet. 1990;170(2):121-125.

5. Zhang JQ, Fielding JR, Zou KH. Etiology of spontaneous perirenal hemorrhage: a meta-analysis. J Urol. 2002;167(4):1593-1596.

6. Hartmann CA. Spontanes bilaterales perirenales Hämatom als Komplikation einer Wegener'schen Granulomatose. [Spontaneous bilateral perirenal hematoma as a complication of Wegener's granulomatosis]. Pathologe. 1987;8(4):237-241. German.

7. Leidig M, Schmiedecke T, John S, Mann J, Weber M. Spontane Nierenruptur als Frühkomplikation einer Wegener-Granulomatose. [Spontaneous kidney rupture as an early complication of Wegener's granulomatosis]. Dtsch Med Wochenschr. 1992;117(12):455-459. German.

8. Tarrass F, Benjelloun M, Medkouri G, Hachim K, Gharbi MB, Ramdani B. Spontaneous kidney rupture - an unusual complication of Wegener's granulomatosis. Nephrol Dial Transplant. 2007;22(1):280.

9. Dammacco F, Sansonno D, Piccoli C, Tucci FA, Racanelli V. The cryoglobulins: an overview. Eur J Clin Invest. 2001;31(7):628-638.

10. Horcajada JP, García-Bengoechea M, Cilla G, Etxaniz P, Cuadrado E, Arenas JI. Mixed cryoglobulinaemia in patients with chronic hepatitis $\mathrm{C}$ infection: prevalence, significance and relationship with different viral genotypes. Ann Med. 1999;31(5):352-358.

11. Saadoun D, Sellam J, Ghillani-Dalbin P, Crecel R, Piette JC, Cacoub P. Increased risks of lymphoma and death among patients with nonhepatitis $\mathrm{C}$ virus-related mixed cryoglobulinemia. Arch Intern Med. 2006;166(19):2101-2108.

12. Trejo O, Ramos-Casals M, García-Carrasco M, et al. Cryoglobulinemia: study of etiologic factors and clinical and immunologic features in 443 patients from a single center. Medicine (Baltimore). 2001;80(4): 252-262.
13. Vasil'ev VI, Probatova NA, Varlamova EIu, et al. Prognosticheskoe znachenie smeshannoĭ monoclonal'noй krioglobulinemii pri bolezni Shegrena. [Prognostic implications of mixed monoclonal cryoglobulinemia in Sjogren's disease]. Ter Arkh. 2004;76(8):61-68. Russian.

14. Ioannidis JPA, Vassiliou VA, Moutsopoulos HM. Long-term risk of mortality and lymphoproliferative disease and predictive classification of primary Sjögren's syndrome. Arthritis Rheum. 2002;46(3):741-747.

15. Ramos-Casals M, Cervera R, Yagüe J, et al. Cryoglobulinemia in primary Sjögren's syndrome: prevalence and clinical characteristics in a series of 115 patients. Semin Arthritis Rheum. 1998;28(3):200-205.

16. Fox RI. Sjögren's syndrome. Lancet. 2005;366(9482):321-331.

17. Achkar AA, Stanson AW, Johnson CM, Srivatsa SS, Dale LC, Weyand CM. Rheumatoid vasculitis manifesting as intra-abdominal hemorrhage. Mayo Clin Proc. 1995;70(6):565-569.

18. Curi MA, Skelly CL, Woo DH, et al. Spontaneous perforation of a nonaneurysmal visceral aorta. Cardiovasc Surg. 2002;10(3):279-283.

19. Klingler JH, Gläsker S, Shah MJ, Van Velthoven V. Rupture of a spinal artery aneurysm attributable to exacerbated Sjögren syndrome: case report. Neurosurgery. 2009;64(5):E1010-E1011.

20. Herold BC, Davis AT, Arroyave CM, Duffy E, Pachman LM, Shulman ST. Cryoprecipitates in Kawasaki syndrome: association with coronary artery aneurysms. Pediatr Infect Dis J. 1988;7(4): $255-257$.

21. Au WY, Kwok JSY, Chu KM, Ma ESK. Life-threatening cryoglobulinemia in HCV-negative Southern Chinese and a novel association with structural aortic abnormalities. Ann Hematol. 2005;84(2):95-98.

22. Smith DL, Wernick R. Spontaneous rupture of a renal artery aneurysm in polyarteritis nodosa: critical review of the literature and report of a case. Am J Med. 1989;87(4):464-467.

23. Ha HK, Lee SH, Rha SE, et al. Radiologic features of vasculitis involving the gastrointestinal tract. Radiographics. 2000;20(3):779-794.

24. Moutsopoulos HM, Avgerinos PC, Tsampoulas CG, Katsiotis PA. Selective renal angiography in Wegener's granulomatosis. Ann Rheum Dis. 1983;42(2):192-195.

25. Pumpe K, Mundinger A, Herbst EW, Peter P. Ungewöhnlicher Verlauf einer Wegener'schen Granulomatose: Erstmanifestation in der Prostata und Ausbildung von arteriellen Mikroaneurysmen in der Niere. [An unusual course of Wegener's granulomatosis: initial manifestation in the prostate and development of arterial microaneurysms in the kidney]. Pathologe. 1989;10(5):318-321. German.

26. Senf R, Jürgensen JS, Teichgräber U, Kampf D, Schindler R. Ruptured arterial aneurysm of the kidney in a patient with Wegener's granulomatosis. Nephrol Dial Transplant. 2003;18(12):2671-2673.
International Medical Case Reports Journal

\section{Publish your work in this journal}

The International Medical Case Reports Journal is an international, peer-reviewed open-access journal publishing original case reports from all medical specialties. Previously unpublished medical posters are also accepted relating to any area of clinical or preclinical science. Submissions should not normally exceed 2,000 words or

\section{Dovepress}

4 published pages including figures, diagrams and references. The manuscript management system is completely online and includes a very quick and fair peer-review system, which is all easy to use. Visit http://www.dovepress.com/testimonials.php to read real quotes from published authors. 